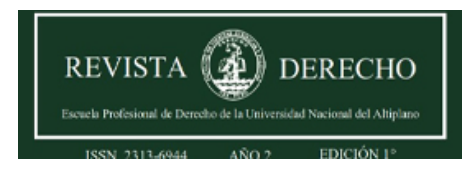

Revista de Derecho

ISSN: 2313-6944

ISSN: 2707-9651

revistaderecho@unap.edu.pe

Universidad Nacional del Altiplano

Perú

\title{
La democracia constitucional como fundamento del control de convencionalidad de normas constitucionales
}

Colque Lizárraga, Alberto

La democracia constitucional como fundamento del control de convencionalidad de normas constitucionales

Revista de Derecho, vol. 6, núm. 2, 2021

Universidad Nacional del Altiplano, Perú

Disponible en: https://www.redalyc.org/articulo.oa?id=671870938004

DOI: https://doi.org/10.47712/rd.2021.v6i2.140

\section{(c) $(1)$}

Esta obra está bajo una Licencia Creative Commons Atribución 4.0 Internacional. 


\section{La democracia constitucional como fundamento del control de convencionalidad de normas constitucionales}

\section{Constitutional democracy as the foundation of conventionality control of constitutional norms}

\author{
Alberto Colque Lizárraga \\ Tribunal Constitucional del Perú, Perú \\ acolque@tc.gob.pe \\ iD https://orcid.org/0000-0002-6974-2139
}

\author{
DOI: https://doi.org/10.47712/rd.2021.v6i2.140 \\ Redalyc: https://www.redalyc.org/articulo.oa? \\ $\mathrm{id}=671870938004$
}

Recepción: 17 Julio 2021

Aprobación: 26 Agosto 2021

Publicación: 13 Septiembre 2021

\section{Resumen:}

El control de convencionalidad que la Corte Interamericana de Derechos Humanos ejerce sobre las normas constitucionales ha despertado críticas que denuncian su falta de legitimidad democrática y su interferencia en la soberanía estatal. Para salvar estas objeciones se recurre al concepto de democracia constitucional y, en específico, al de constitucionalismo garantista; reconociendo, de esta manera, la existencia de una "esfera de lo indecidible interamericana" que sirve de límite a las decisiones estatales. Asimismo, se plantea una nueva concepción de la soberanía estatal que, conforme al modelo garantista, se fragmenta en los derechos humanos contenidos en los tratados internacionales que los Estados han ratificado.

Palabras clave: Democracia constitucional, control de convencionalidad, legitimidad democrática, normas constitucionales, poder constituyente.

\section{Abstract:}

The conventionality control that the Inter-American Court of Human Rights exercises over constitutional norms has aroused criticism that denounces its lack of democratic legitimacy and its interference in state sovereignty. To overcome these objections, we resort to the concept of constitutional democracy and, specifically, to a version of constitutionalism that is essentially defined in terms of guarantee; recognizing, in this way, the existence of an "inter-American sphere of the undecidable" that serves as a limit to state decisions. Likewise, a new conception of state sovereignty is proposed that, according to the guarantee model, is fragmented in the human rights contained in the international treaties that the states have ratified.

KEYWORDS: Constitutional democracy, conventionality control, democratic legitimacy, constitutional norms, constituent power.

\section{INTRODUCCIÓN}

Uno de los avances más importantes en materia de protección de derechos humanos dentro de nuestra región es el referido al control de convencionalidad, el cual, ejercido por la Corte Interamericana de Derecho Humanos, se ha convertido en una herramienta relevante para la garantía de los derechos reconocidos en tratados internacionales. Sin embargo, su ejercicio recientemente ha despertado algunas críticas que cuestionan su competencia para controlar determinadas normas estatales como la propia constitución. Esto ha generado cierta renuencia por parte de los Estados para el debido cumplimiento de las sentencias de la Corte Interamericana.

El presente trabajo tiene por objetivo conciliar las objeciones planteadas por parte del orden estatal a la labor de la Corte IDH, las cuales suelen referirse a su falta de legitimidad democrática y su supuesta injerencia en la soberanía estatal. Para ello se recurre, en primer lugar, al concepto de democracia constitucional y, específicamente, a la propuesta del constitucionalismo garantista, ello con la intención de plantear las bases teóricas del debate sobre la dificultad contramayoritaria. Posteriormente se sugiere, a partir de los propios 
pronunciamientos de la Corte IDH, la existencia de una democracia constitucional a nivel interamericano, la cual, al ser enfocada desde la perspectiva del constitucionalismo garantista, permitirá justificar el ejercicio del control de convencionalidad de normas constitucionales cuando este tenga por finalidad la protección de los derechos que conforman la "esfera de lo indecible interamericana" y se desenvuelva dentro de un estrecho margen de discrecionalidad. Finalmente se realiza un análisis del poder constituyente desde la teoría del derecho para justificar su sujeción a la democracia constitucional.

\section{CONTROL DE CONVENCIONALIDAD, LEGITIMIDAD DEMOCRÁTICA Y SOBERANÍA}

La Corte Interamericana de Derechos Humanos (en adelante Corte IDH) ha instaurado el control de convencionalidad con la finalidad de expandir el cumplimiento de la Convención Americana sobre Derechos Humanos $(\mathrm{CADH})$ en los Estados que la hayan ratificado. Este control "se concentra en las normas de rango legal, interpretaciones de la ley que realizan los tribunales nacionales, omisiones legislativas y [en] el control de normas constitucionales" (Torres, 2016, p. 218). Su ejercicio ha tenido grandes avances en los últimos años, desplegándose en la mayoría de Estados a través de un modelo difuso, sin encontrar mayores resistencias para su implementación. Sin embargo, en su versión concentrada, es decir, en la facultad que la Corte IDH tendría para inaplicar las normas internas, no existe consenso sobre su legitimidad, sobre todo cuando este control se enfoca en normas con un profundo mérito democrático, como son aquellas aprobadas por referéndum o, más aún, cuando se concentra sobre normas constitucionales.

Las constituciones estatales han sido objeto de control por parte de la Corte IDH, tanto a través de su función consultiva como contenciosa. Así se tiene que en la Opinión Consultiva OC-4/84 del 19 de enero de 1984, a solicitud del Estado de Costa Rica, la Corte IDH analizó la compatibilidad de un proyecto de reforma constitucional que incidía sobre el derecho a la nacionalidad. En esa oportunidad, si bien la materia de consulta no fue una norma constitucional vigente, ello no fue óbice para que la Corte IDH ejerciese su función consultiva y, en consecuencia, un control de convencionalidad preventivo (conforme lo estableció más adelante en la opinión consultiva OC-22/16). Por otro lado, respecto a su función contenciosa, la Corte IDH ha controlado convencionalmente normas constitucionales en casos tales como Olmedo Bustos y otros vs. Chile, Boyce y otros vs. Barbados y en el caso Caesar vs. Trinidad y Tobago, en los cuales dispuso que estos Estados debían -respectivamente- modificar, eliminar el efecto y enmendar, determinados aspectos de sus constituciones. Es por ello que el control desplegado por la Corte IDH ha generado críticas dirigidas a denunciar su falta de legitimidad democrática y una supuesta afrenta a la soberanía estatal.

Ante esa problemática se forman dos frentes, los cuales postulan la primacía de un ordenamiento jurídico sobre otro. Quienes defienden los ordenamientos nacionales, y en consecuencia, el principio de supremacía de la constitución, refieren que los fallos de la Corte IDH que condenan a un Estado, deben ser objeto de estricto cumplimiento siempre y cuando no importen, a su vez, una violación a los preceptos de la constitución (Baldeni, 2010, p. 398); por lo que no es posible aceptar la jurisdicción de un organismo que puede, eventualmente, dictar fallos contrarios a este tipo de normas pues, "si se aceptara que una Corte cualquiera pudiese dictar fallos contrarios a la Constitución, esa ley que acepta la jurisdicción de la Corte sería en sí misma inconstitucional" (Pastori Fillol, 2011, p. 190). Por otro lado, en defensa del derecho internacional se afirma que, argumentos como los antes señalados pierden fuerza cuando son contrapuestos al contenido del artículo 68.1 de la CADH, que establece el compromiso de los Estados de cumplir con lo ordenado en las sentencias de la Corte IDH, el cual puede verse reforzado, a la vez, por lo dispuesto en el artículo 27 de la Convención de Viena sobre el Derecho de los Tratados, en el sentido de que el Estado no puede invocar disposiciones de su derecho interno con el fin de incumplir lo dispuesto por la Corte IDH.

Como puede apreciarse, el enfrentamiento entre ambas propuestas se caracteriza por enmarcarse en un contexto dogmático de la problemática, es decir, se basa en la interpretación de las normas contenidas tanto en las constituciones como en los instrumentos internacionales en materia de derechos humanos. Tal 
pugna genera que la discusión se someta a una lógica dualista en cuanto a la relación entre ambos sistemas; asumiéndose la existencia de "ordenamientos distintos y separados, recíprocamente independientes, en el sentido que cada uno de ellos tiene su propio fundamento de validez, es decir, una norma suprema propia" (Guastini, 2016, p. 83). Este dualismo enfrenta, en última instancia, a los fundamentos de validez de cada ordenamiento, siendo en el caso del derecho interno de los Estados una constitución y en el caso del derecho internacional, la CADH y todos los tratados internacionales en materia de derechos humanos que los Estados hayan ratificado.

En el caso específico del control de convencionalidad de normas constitucionales, la resistencia de los defensores de la primacía de la constitución y, en términos generales, del ordenamiento jurídico interno, parece concentrarse en dos objeciones claras; la primera, referida a la legitimidad democrática que tendría la Corte IDH para ejercerlo y, en segundo lugar, la afectación que se ocasionaría a la soberanía estatal. Para sostener debidamente este control se debe, en todo caso, buscar una fórmula que concilie al mismo tiempo las agresiones al principio democrático y a la soberanía estatal. Para ello, la discusión debe abstraerse del debate meramente formal que plantea una confrontación dogmática de la interpretación normativa, y evaluar también los efectos en la esfera política. Una forma de lograr ese objetivo es recurrir al concepto de democracia constitucional, y, específicamente, a la concepción que de esta tiene el constitucionalismo garantista.

\section{Democracia constitucional}

De acuerdo a Pedro Salazar (2006), la democracia constitucional es "un modelo de organización políticojurídica en el que confluyen diversas tradiciones del pensamiento político moderno y que persiguen en un solo momento dos objetivos analíticamente distintos: limitar el poder político y distribuirlo entre los ciudadanos" (p. 45). Visto de ese modo, el constitucionalismo democrático -como también suele llamársele- surge de la integración de la democracia y el constitucionalismo como sistemas independientes, acontecimiento que de acuerdo a Fernando Álvarez (2003), comenzó a desarrollarse a finales del siglo XVIII. Esta conjunción no se trata solo de una suma partes, sino que conlleva un valor agregado o, como dice Carlos Santiago Nino (1997), "la democracia constitucional es una forma de gobierno muy superior a la democracia pura o al gobierno constitucional no democrático". (p. 13)

Sin embargo, pese a las virtudes de la democracia constitucional, es inevitable avizorar en su interior permanentes conflictos que surgen como consecuencia de los fines, particularmente distintos y hasta cierto grado opuestos, del constitucionalismo y la democracia, pues mientras la democracia implica empoderar al pueblo imbuyéndolo del poder político, el constitucionalismo se dirige a limitarlo o, visto a la inversa, mientras el constitucionalismo tiene por finalidad limitar el ejercicio del poder político, la democracia se lo entrega al pueblo. En tal sentido, se genera un conflicto entre el principio democrático, por el cual las mayorías -y sus representantes- toman decisiones, y el control constitucional de las leyes que realizan los jueces como consecuencia de la supremacía constitucional; ello debido a que desde el constitucionalismo pueden entenderse a los derechos fundamentales como espacios de decisión sustraídos de la política democrática, en otras palabras, donde hay un derecho fundamental, el legislador encuentra un límite para decidir sobre ciertas cosas (Pino, 2018, p. 104).

Este problema suele denominarse "dificultad contramayoritaria", y toma la forma de una crítica dirigida contra el ejercicio del control de constitucionalidad, alegándose la falta de legitimidad democrática de los jueces para controlar las leyes dadas por la ciudadanía a través de sus representantes. Alexander Bickel (1962, pp. 16-17), quien acuñó el término, menciona que la dificultad radica en que el control de constitucionalidad es una fuerza contramayoritaria, pues cuando se declara inconstitucional una ley, se tuerce la voluntad de los representantes del pueblo y en tal sentido, no se ejerce el control en nombre de la mayoría, sino en su contra. Así expresado, la relación entre el control de constitucionalidad y la democracia implicaría un eterno problema (Alexy, 2006, p. 12), pues "si la democracia es el método de toma de decisiones por mayoría, la 
primacía constitucional implica precisamente restricciones a lo que la mayoría puede decidir”. (Bayón, 2005, p. 214)

Nótese, sin embargo, que el elemento desencadenante de la dificultad contramayoritaria no radica en el control de constitucionalidad per se, sino en ciertas condiciones rígidas de su ejercicio, como son el que este control deba desarrollarse exclusivamente por los jueces -entendiéndolos como "órganos de cierre" dentro de la jurisdicción interna- o que se entienda a los derechos fundamentales como "cotos vedados" cuya discusión sobre sus contenidos quede a exclusiva discrecionalidad interpretativa de los jueces. De esta manera, la dificultad contramayoritaria no se extinguirá del todo a menos que fallen condiciones tales como la existencia de una constitución rígida y la consagración de un modelo robusto de control judicial de las leyes (Linares, 2008 , p. 242). Es por ello que sistemas con un modelo de revisión judicial débil -como el canadiense-, donde la última palabra institucional la tiene el órgano legislativo y no los jueces, suelen ser aceptados como más deferentes al principio democrático y, por lo tanto, libres de la dificultad contramayoritaria.

En Canadá los parlamentarios no solo tienen la facultad de reformular una ley que haya sido declarada inconstitucional o derogar las decisiones de los jueces constitucionales (cláusula override), también pueden aprobar leyes contrarias a la constitución (cláusula notwithstanding). Estas facultades, reconocidas en el artículo 33 de la Constitución canadiense, tienen como condiciones que el órgano legislativo haga referencia expresa de su aplicación y que la vigencia de las leyes dictadas sea de cinco años, con la posibilidad de ser prorrogadas. De esta manera, Federico de Montalvo (2012, p. 399) refiere que el control de constitucionalidad ejercido por el Tribunal Supremo canadiense se vería completado por la posibilidad que se atribuye al legislador de contradecir, modificar o evitar sus decisiones, creándose un diálogo entre ambos poderes. Esta es una propuesta defendida por el constitucionalismo dialógico que entiende que "en una democracia, la interpretación constitucional tiene que ser el resultado de una conversación horizontal, colectiva e inclusiva, y no una imposición desde arriba" (Gargarella, 2017, p. 164).

Así entendido el problema, es posible sortear el conflicto entre democracia y constitucionalismo a través del diálogo interinstitucional, pues a través de la deliberación se establecen determinados parámetros para el ejercicio del control de constitucionalidad. De esta manera, se tiene que la idea de estas propuestas es "mantener el control de las leyes dentro de ciertos límites que hoy no existen, y que han determinado la entronización del órgano de control como vértice de la estructura institucional" (Gargarella, 2011, p. 195).

Pese a ello, el diseño del Sistema Interamericano de Protección de los Derechos Humanos no es lo suficientemente maleable como para poder implementar una versión del constitucionalismo dialógico canadiense, pues en este persiste la existencia de la rigidez de las normas de reconocimiento contenidas en la $\mathrm{CADH}$ y, por otro lado, la existencia de un robusto y centralizado sistema de control de convencionalidad. En ese sentido, si bien la democracia constitucional es un buen punto de partida para encontrar una respuesta a los cuestionamientos al ejercicio de la Corte IDH que denuncian agresiones a la soberanía estatal y su falta de legitimidad democrática, las virtudes de su versión deliberativa se ven limitadas por su propio diseño institucional.

\section{Constitucionalismo garantista}

En términos generales para Ferrajoli el garantismo es un modelo de derecho que se basa en la rígida subordinación de todos los poderes a la ley y a los derechos fundamentales reconocidos en la constitución (Ferrajoli, 2014, p. 29). De tal forma que en un modelo garantista no hay lugar para poderes absolutos o potestas legibus soluta -como recurrentemente los denomina-, agregando que esta limitación contiene a toda forma de ejercicio del poder que incluye a los poderes públicos, privados, políticos o económicos, en el plano estatal o en el internacional (Ferrajoli, 2008, p. 62). Es bajo esos estándares que se desprende una concepción particular de la relación entre democracia y constitucionalismo. 
Efectivamente, Ferrajoli propone que la democracia constitucional tiene dos dimensiones, una formal o procedimental, relativa a las formas y a los procedimientos utilizados para la toma de las decisiones; y una dimensión sustancial, relativa a lo que no puede ser o debe ser decidido por cualquier mayoría (2011, p. 35). De esta manera, la dimensión formal es un requisito sine qua non en ausencia del cual no se puede hablar propiamente de democracia, pero es insuficiente para identificar todos los elementos necesarios que permitan calificar a un sistema político de democrático (Ferrajoli, 2008, p. 78). Por lo tanto, se requiere de una dimensión sustancial que la complete, la que, según refiere el maestro florentino, está expresada por los derechos fundamentales, los cuales conforman una suerte de "esfera de lo indecidible" que se sustrae de la voluntad de las mayorías (2008, p. 102).

Desde ese punto de vista podría advertirse que la democracia sustancial de Ferrajoli no es otra cosa que el sistema que nace de la supremacía constitucional (constitucionalismo), mientras que la democracia formal corresponde al sistema de la democracia propiamente dicha (Salazar Ugarte, 2006, p. 216). La particularidad, sin embargo, es que la democracia constitucional, bajo los parámetros del garantismo, pretende integrar al constitucionalismo y la democracia en un modelo coherentemente estructurado, salvando su caótica relación al someterlos bajo las garantías de los derechos fundamentales que la constitución reconoce. Esta particularidad incide directamente sobre la soberanía y la legitimidad democrática, justamente los problemas que enfrenta la Corte IDH en su ejercicio.

\subsection{Soberanía popular}

Para el modelo que plantea Ferrajoli la soberanía no puede entenderse como un poder absoluto pues “cualquier concepción de la soberanía como potestas legibus soluta está en contradicción no sólo con el modelo de la democracia constitucional sino con la idea misma de democracia” (2013b, p. 13). En ese sentido, se ve obligado a deconstruir la soberanía para implementarla dentro de su propuesta democrática constitucional, para ello Ferrajoli plantea, en primer lugar, distinguir un significado negativo de soberanía popular, el cual se encuentra previsto en la mayoría de constituciones con fórmulas tales como "la soberanía reside en el pueblo", en un sentido literal esta norma equivale a una garantía negativa, por la cual "la soberanía pertenece al pueblo y a ningún otro, y ninguno -presidente o asamblea representativa- puede apropiarse de ella o usurparla" (Ferrajoli, 2012, p. 27). Por otro lado, la soberanía popular, esta vez en un sentido positivo, se relaciona con los derechos fundamentales y, por lo tanto:

pertenece al conjunto de sus ciudadanos, es decir, de todas las personas de las que el pueblo se compone: pertenece, en una palabra, a todos y a cada ciudadano en cuanto equivale a la suma de aquellos poderes y contrapoderes [...] que son los derechos fundamentales constitucionalmente establecidos. (Ferrajoli, 2013b, p. 14)

De esa manera, para Ferrajoli los derechos fundamentales son fragmentos de soberanía y cualquier violación a ellos representa una lesión no sólo a las personas que son sus titulares, sino también a la soberanía popular (2013b, p. 14). Esta forma de concebir la soberanía será útil más adelante para entender la verdadera injerencia que las decisiones de la Corte IDH tienen sobre la soberanía de los Estados.

\subsection{Legitimidad democrática}

Un elemento central en la democracia constitucional de Ferrajoli es el concepto de "esfera de lo indecidible", la cual, siguiendo la línea del "coto vedado" de Garzón Valdez o del "territorio inviolable" de Norberto Bobbio, plantea la existencia de un "conjunto de principios que, en democracia, están sustraídos a la voluntad de las mayorías" (Ferrajoli, 2008, p. 102). La particularidad, sin embargo, está en que la esfera de lo indecidible deja de ser un concepto de la filosofía política para integrarse a la teoría del derecho, ello como consecuencia de 
su reconocimiento por las constituciones rígidas; asimismo, esta esfera no solo hace referencia a un territorio prohibido, sino también a uno obligado, es decir, no solo implica lo que no puede ser decidido (derechos de libertad), sino también lo que no puede dejar de ser decidido (derechos sociales). Por último, la esfera de lo indecidible de Ferrajoli no solo se impone como un límite a los poderes públicos sino también a los privados, es decir, no solo al Estado sino también al mercado. (Ferrajoli, 2008, pp. 102-104)

Considerando que de acuerdo al modelo de Ferrajoli le corresponde a la jurisdicción constitucional salvar las lagunas y antinomias que incidan sobre las garantías de los derechos fundamentales que conforman la esfera de lo indecidible, su propuesta no está exenta de la dificultad contramayoritaria y, en esos términos, sería contraria en sí misma al otorgar a los jueces la última palabra y, en consecuencia, imbuirlos de un poder cuasi absoluto, ello si recordamos la sentencia de Hobbes (2000) al referir que: "aquel cuya autoridad es limitada no es rey, sino que el rey es el súbdito que le limita" (p. 143). Sin embargo, el modelo de Ferrajoli no empodera de forma absoluta a los jueces, por el contrario, los somete a los límites que la propia ley y la constitución establecen. Es decir, si bien su legitimidad democrática se encuentra comprometida, ello no quiere decir que no se encuentren legitimados para ejercer el control de constitucionalidad. Tomando en cuenta que la jurisdicción constitucional tiene por finalidad la determinación de validez constitucional de las leyes, Ferrajoli considera que la fuente de legitimación de los jueces no es la fuente político-representativa propia de las instituciones de gobierno, sino la sujeción a la ley (2006, p. 97).

Para Jeremy Waldron (2018) el problema del control de constitucionalidad tiene que ver con el "peligro de que la autoridad judicial desbalancee la constitución, aprovechándose del poder de los tribunales para revisar el trabajo de otras instituciones y de ese modo establecer su preeminencia en el esquema constitucional" (p. 140). Este peligro logra desvanecerse con modelos como el del constitucionalismo dialógico, sin embargo, la propuesta de Ferrajoli también parece dirigirse a atacar los riesgos denunciados por Waldron, pero a través de una estrategia distinta, no procurando otorgar legitimidad democrática a los jueces sino limitándolos en su ejercicio. En coherencia con el leitmotiv del constitucionalismo garantista, el poder de los jueces no puede ser absoluto, en consecuencia:

el paradigma garantista del constitucionalismo rígido requiere que el poder judicial sea lo más limitado posible y vinculado por la ley y por la constitución, según el principio de la separación de los poderes y la naturaleza de la jurisdicción, tanto más legítima cuanto más cognoscitiva y no discrecional. (Ferrajoli, 2012, p. 50)

Queda claro, entonces, que el control de constitucionalidad se encuentra legitimado por el estricto cumplimiento que los jueces hagan de la constitución y la ley, de ahí que Ferrajoli sea un crítico del constitucionalismo principialista, precisamente porque la conexión entre derecho y moral rompe con la lógica positivista en la que su modelo apoya la legitimidad del control de constitucionalidad:

si se sostiene que los jueces no deben limitarse a interpretar las normas de derecho positivo, sino que también están habilitados para crear ellos mismos normas, aunque sólo sea a través de la ponderación de los principios, entonces resulta anulada la separación de los poderes. (Ferrajoli, 2012, p. 44)

El peligro que Ferrajoli encuentra en el constitucionalismo principialista es, en gran medida, el mismo que advierte Waldron al criticar el control judicial de las leyes; pues al adoptarse la doctrina de los principios, el juez constitucional puede convertirse en un poder supremo, que ningún otro poder podría frenar (Guastini, 2015, p. 342). De esta manera, el constitucionalismo garantista pretende limitar todo poder, incluido también el de los jueces al ejercer el control de constitucionalidad.

\section{DEMOCRACIA CONSTITUCIONAL Y CONTROL DE CONVENCIONALIDAD}

En nuestra región el derecho internacional se articula con los ordenamientos nacionales para dar origen a un complejo sistema de protección de los derechos humanos. Se presenta una protección a nivel nacional a través 
de todas las garantías que los Estados establecen para la defensa de los derechos previstos en sus respectivas constituciones y una garantía a un nivel internacional gracias a la protección otorgada por la CADH y el Sistema Interamericano de Protección de los Derechos Humanos. Sin embargo, como evidenciamos al principio, la relación entre ambos ordenamientos encuentra dificultades como consecuencia del control de convencionalidad que ejerce la Corte IDH sobre las normas nacionales con profunda raigambre democrática, como son las normas constitucionales o las leyes ratificadas por procesos de democracia directa. Su ejercicio, por lo tanto, motiva cuestionamientos a su falta de legitimidad democrática y su injerencia en la soberanía estatal.

\subsection{Soberanía estatal y derecho internacional de los derechos humanos}

El conflicto señalado nace de una visión dogmática de la relación que existe entre el ordenamiento nacional y el internacional, en el cual se reconocen dos fundamentos de validez contrapuestos. Sin embargo, esta visión deja de lado un cambio de paradigma que se ha instaurado con el desarrollo del derecho internacional de los derechos humanos, por el cual los tratados internacionales sobre la materia "no debe $[\mathrm{n}]$ considerarse como un medio para integrar recíprocamente intereses entre los Estados sino un medio para el establecimiento de un orden público común, cuyos destinatarios no son los Estados, sino los seres humanos”. (Nikken, 1987, p. 90)

Este cambio incide directamente en la concepción de soberanía estatal, pues la ratificación de tratados internacionales en materia de derechos humanos se traduce en el reconocimiento que los Estados hacen a nivel internacional de sus compromisos frente sus ciudadanos; de tal forma que, si desde la perspectiva del constitucionalismo garantista la soberanía popular no es otra cosa que la suma de aquellos fragmentos de soberanía que son los derechos de todos (Ferrajoli, 2012, p. 28), con el reconocimiento de los derechos humanos contenidos en los tratados internacionales, los Estados fragmentan su soberanía en favor de sus ciudadanos con el aval de la comunidad internacional. Este criterio es precisamente el que la Corte IDH ha asumido en la Opinión Consultiva OC-2/82, en la que estableció que:

Los tratados modernos sobre derechos humanos, en general, y, en particular, la Convención Americana, no son tratados multilaterales de tipo tradicional, concluidos en función de un intercambio recíproco de derechos, para el beneficio mutuo de los Estados contratantes. Su objeto y fin son la protección de los derechos fundamentales de los seres humanos, independientemente de su nacionalidad, tanto frente a su propio Estado como frente a los otros Estados contratantes. Al aprobar estos tratados sobre derechos humanos, los Estados se someten a un orden legal dentro del cual ellos, por el bien común, asumen varias obligaciones, no en relación con otros Estados, sino hacia los individuos bajo su jurisdicción. (párrafo 29)

De esta manera, no resulta coherente alegar vulneraciones a la soberanía estatal cuando la Corte IDH realiza el control de convencionalidad, incluso si esté recae sobre normas constitucionales, pues su ejercicio se encuentra fundamentado en los compromisos que los Estados han asumido frente a sus ciudadanos. No se trata de una injerencia de la Corte IDH sino de la garantía de esos compromisos. A pesar de esto, el control de convencionalidad de normas constitucionales aun es materia de cuestionamiento desde el punto de vista de su legitimidad democrática, pues es innegable que, con su despliegue, la Corte IDH se enfrenta a una contundente dificultad contramayoritaria.

\subsection{Corte IDH y legitimidad democrática}

Sobre la legitimidad democrática de la Corte IDH, Diana Hernández (2014, pp. 36-37) realiza un análisis distinguiendo una legitimidad de origen y otra de resultado; de esta manera, su legitimidad democrática de origen se relaciona con el origen democrático de la institución, su cercanía con la voluntad popular y su nivel de representación, mientras que su legitimidad democrática de resultado alude al ejercicio y finalidad 
del control de convencionalidad, siendo su principal fundamento los derechos humanos. En tal sentido, se concluye que en el ejercicio del control de convencionalidad la Corte IDH tiene un grado mínimo de legitimidad de origen y un grado medio de legitimidad de resultado (2014, p. 147). Sin embargo, el grueso del fundamento se encontraría en la legitimidad democrática de resultado, es decir, en la defensa de los derechos humanos, lo que otorgaría a la Corte IDH la suficiente legitimidad como para controlar incluso normas constitucionales pues, "en la medida en que el control de convencionalidad de la Constitución y la ley de un Estado parte de la Convención sirva para garantizar los derechos y libertades humanas, el grado de legitimidad es alto”. (Hernández Castaño, 2014, p. 150)

Sobre la base de estas ideas es posible recurrir a los desarrollos del constitucionalismo garantista para reconocer la legitimidad de la Corte IDH en la protección de los derechos humanos, los cuales, conformarían una suerte de esfera de lo indecidible a nivel interamericano. Es precisamente esa la estrategia utilizada por la Corte IDH en el caso Gelman vs. Uruguay para fundamentar su legitimidad al oponerse a una ley ratificada por procedimientos de democracia directa; en esa oportunidad la Corte IDH estableció que:

\footnotetext{
La legitimación democrática de determinados hechos o actos en una sociedad está limitada por las normas y obligaciones internacionales de protección de los derechos humanos reconocidos en tratados como la Convención Americana, de modo que la existencia de un verdadero régimen democrático está determinada por sus características tanto formales como sustanciales, por lo que, particularmente en casos de graves violaciones a las normas del Derecho Internacional de los Derechos, la protección de los derechos humanos constituye un límite infranqueable a la regla de mayorías, es decir, a la esfera de lo "susceptible de ser decidido" por parte de las mayorías en instancias democráticas, en las cuales también debe primar un control de convencionalidad. (párrafo 239)
}

La Corte IDH es bastante clara al reconocer un límite al principio democrático, pues, si bien reconoce la existencia de una esfera de lo "susceptible de ser decidido" contrario sensu es posible suponer la existencia de una esfera de lo que no está permitido ser decidido o, usando la terminología de Ferrajoli, una esfera de lo indecidible, la cual, en este caso, contendría todos aquellos derechos humanos reconocidos por la CADH y demás tratados sobre la materia ratificados por los Estados. Sin embargo, es posible ir más allá y percatar la existencia de "un marco mínimo de protección conformado por el catálogo de derechos y obligaciones básicas que resulta de la convergencia de los listados constitucionales y los instrumentos regionales" (Acosta, 2017, p. 382). Esta suerte de esfera de lo indecidible interamericana vincula transversalmente a los Estados a través de los derechos reconocidos, tanto por las cartas constitucionales como por los tratados internacionales, de tal suerte que se establecen "límites y vínculos ya no sólo constitucionales sino supraestatales, externos además de internos, a la potestad de los Estados". (Ferrajoli, 2013b, p. 479)

Las garantías de la esfera de lo indecidible interamericana se materializan con la protección que de ella hacen la Corte IDH y los jueces nacionales, a través de un ejercicio sincrónico motivado por el principio pro personae. Se trata de un permanente diálogo entre las cortes pues, así como los jueces nacionales recurren a la jurisprudencia de la Corte IDH para decidir los casos sujetos a su conocimiento, esta reconoce en su propia actuación judicial el valor que tienen los criterios definidos por las cortes nacionales cuando otorgan un mayor nivel de protección a los derechos humanos (Ferrer Mac-Gregor, 2016, p. 349). Esta actividad se enmarca dentro del enfoque transformador del ius constitutionale commune latinoamericano, el cual persigue como ideal el cumplimiento de las promesas de las constituciones estatales de la región, apostando por un discurso que interrelacione los distintos ordenamientos jurídicos, nacionales e internacional (Von Bogdandy, 2015, pp. 13-21).

\subsection{Discrecionalidad de la labor de la Corte IDH}

De acuerdo a lo desarrollado líneas arriba, la legitimidad de los jueces, en la lógica del constitucionalismo garantista, se encontraría en su sujeción a la ley y a la constitución en clave positivista, es decir, estableciendo un estrecho margen de discrecionalidad para la labor judicial. De esta manera, si bien la Corte IDH parece 
reconocer como fundamento la existencia de una democracia constitucional a nivel interamericano, las objeciones que se han esgrimido en contra del control de convencionalidad de normas constitucionales solo podrán desaparecer si este se realiza con sujeción a lo expresamente establecido en los tratados internacionales, debiendo desestimarse en lo posible cualquier labor activista por parte de la Corte IDH.

$\mathrm{Al}$ hacer una revisión de los casos en los que la Corte IDH realizó un control de normas constitucionales tenemos que, en general, se evidenciaron violaciones a derechos expresamente reconocidos en la CADH. Así se tiene que en el caso "La Última Tentación de Cristo" (Olmedo Bustos y otros) vs. Chile, la Corte IDH realizó un control de la Constitución chilena pues encontró que esta atentaba directamente contra el derecho a la libertad de pensamiento y de expresión, el cual se encuentra reconocido en el artículo 13 de la CADH. En el caso Boyce y otros vs. Barbados, la Corte IDH determinó la violación del derecho a la vida, reconocido en el artículo 25 de la CADH. En el caso Caesar vs. Trinidad y Tobago, por otro lado, el control de convencionalidad se justifica por una violación al derecho a la integridad personal, previsto en el artículo 5 de la CADH.

De estos casos puede verse que la Corte IDH ha realizado interpretaciones con sujeción a normas expresamente establecidas en la $\mathrm{CADH}$, por lo que sus facultades se encontraban limitadas por el contenido literal de este tratado internacional, el cual, como se señaló, refleja la fragmentación de la soberanía estatal, de tal forma que, al ceñirse a su orden literal, la Corte IDH no hace más que efectivizar el compromiso que los Estados han realizado para con sus ciudadanos. Sin embargo, la labor de la Corte IDH algunas veces se reviste de un activismo judicial que la aleja de los parámetros de la democracia constitucional, incluso cuando controla de normas con profunda raigambre democrática, así se tiene, por ejemplo, que respecto del caso Gelman vs. Uruguay, se ha dicho que:

una de las principales razones alegadas por la Corte IDH para condenar a Uruguay por su incumplimiento con el Derecho Internacional de los Derechos Humanos vigente, tiene que ver con un artículo de la Convención que en ningún momento hace referencia más o menos explícita a los deberes de "prevenir," "investigar", "sancionar", restablecer y "reparar" los "daños producidos por la violación de los derechos humanos” deberes que, según la Corte IDH, Uruguay no habría cumplimentado. (Gargarella, 2013, p. 13)

Resulta paradójico que es precisamente este caso en el que la Corte IDH hace alusión a la esfera de lo indecidible, tomando como inspiración el modelo del constitucionalismo garantista de Ferrajoli.

\section{Control DE CONVENCIONALIDAD Y PODER CONSTITUYENTE}

Salvadas las objeciones relativas a la soberanía estatal y la dificultad contramayoritaria de la Corte IDH, queda preguntarnos si esto es suficiente para reconocer la facultad de controlar convencionalmente las constituciones estatales. Al respecto la resistencia más evidente a esta situación es la que está referida al poder constituyente, pues este suele ser concebido como un poder absoluto, sin embargo, esto dependerá del punto de vista que se tome, pues el poder constituyente es un concepto central tanto de la filosofía política como de la teoría del derecho (Ferrajoli, 2013a, p. 804) y, por lo tanto, su forma de entenderlo diverge conforme la disciplina en la que se analice.

Ver al poder constituyente desde la teoría del derecho es útil gracias a su sutil simpleza. En términos teóricos, el poder constituyente no es más que el poder de instaurar una primera constitución, entendiendo por primera constitución a aquella que no encuentra su fundamento de legitimidad en una precedente (Guastini, 2001, p. 40). Efectivamente, el poder constituyente plantea una tabula rasa para el ordenamiento jurídico, por lo que, solo en esos términos, es un poder desregulado y con el potencial de imponerse sobre el ordenamiento jurídico vigente, de ahí que sea, respecto a este, un poder ilegal y, en específico, inconstitucional respecto de la constitución que reemplaza. En tal sentido, desde la teoría del derecho el poder constituyente es "reconocible únicamente a posteriori, a partir del ordenamiento efectivamente producido 
como consecuencia de su ejercicio" (Ferrajoli, 2013a, p. 806), en ausencia de un nueva constitución no tiene sentido hablar de poder constituyente.

Esta forma de entender al poder constituyente nos permite eludir la idea de que una constitución solo es tal si es dada por el pueblo soberano, un escenario más parecido a un anhelo de la filosofía política antes que al reflejo de la experiencia constitucional. Es evidente que no todas las constituciones han sido producto de una verdadera voluntad popular, por el contrario, muchas de ellas han sido impuestas por regímenes autoritarios o incluso por gobiernos extranjeros. Si se parte de la idea de que el poder constituyente solo puede ser ejercido por el pueblo, ello nos llevaría a la paradoja de afirmar que en todos los otros casos lo Estados no tienen una verdadera constitución, afirmación que en términos políticos puede resultar relevante para plantear legítimos procesos constituyentes, pero que en términos de la teoría del derecho es insostenible.

En tal sentido, si el poder constituyente es solo el poder de darse una nueva constitución, es irrelevante quien lo ejerza. Si de lo que se trata es de instaurar una constitución democrática, las exigencias desde la teoría son otras, pues la naturaleza popular del sujeto constituyente no es garantía suficiente para que la constitución que se establezca tenga un cariz democrático. Siguiendo a Ferrajoli (2013a), es necesario distinguir la democraticidad del acto constituyente de la democraticidad de la constitución producida, y en tal sentido, sostener que "una constitución es democrática porque representa una garantía para todos, y no porque es querida por todos o por una mayoría cualquiera”. (p. 812)

Como ya ha quedado sentado, estas garantías son los derechos reconocidos por las constituciones y, gracias al desarrollo del derecho internacional de los derechos humanos, también los derechos reconocidos en los tratados internacionales sobre la materia. Vistos estos derechos como fragmentos de soberanía y compromisos del Estado para con sus ciudadanos, el control que la Corte IDH realice sobre normas constitucionales se traduciría en un test democrático, por el cual es posible denunciar que la calidad democrática de las constituciones no se ajusta a los estándares que los propios Estados se comprometieron a respetar. De esta manera, desde la teoría del derecho, el poder constituyente no representa un obstáculo para el ejercicio del control de convencionalidad, pues éste no se opone a la constitución, sino que participa en la tarea de elevar su calidad democrática.

Por otro lado, el control de la Corte IDH si podría encontrar resistencias en el poder constituyente visto desde la filosofía política, desde la cual puede entenderse como una manifestación de la voluntad popular. Frente a este escollo pueden plantearse dos argumentos, el primero ya ha sido tratado líneas arriba y tiene que ver con la instauración de la esfera de lo indecidible interamericana, la cual representaría un límite infranqueable, incluso para el poder constituyente originario que, desde el punto de vista político, es una manifestación del principio democrático.

El segundo argumento tiene que ver con los límites que el derecho internacional impone al poder constituyente, en el sentido de que los derechos asegurados por tratados internacionales ratificados y vigentes también constituyen límites a la soberanía, pues el propio Estado mediante su ratificación los ha considerado como tales (Nogueira Alcalá, 2009, p. 69). Es el Estado quien, en un momento de lucidez decide voluntariamente y con el aval de la comunidad internacional, limitar todo ejercicio del poder, incluido un eventual poder constituyente. Sin embargo, "los tratados internacionales en vigor no suponen un obstáculo insuperable para la adopción de normas constitucionales que se reputen de importancia mayor" (Diez-Picazo, 2006, p. 15); bastaría, en todo caso, que el Estado denuncie el tratado internacional para poder eludir sus efectos. Es por ello que esta limitación se convierte más bien, en una suerte de filtro de la voluntad del poder constituyente que sirve para disuadir su ejercicio autoritario.

\section{REFLEXIONES FINALES}

El presente trabajo ha pretendido ofrecer una respuesta que permita disipar las objeciones que se plantean contra la Corte IDH cuando ejerce el control de convencionalidad de normas constitucionales. De esta 
manera, a partir del modelo propuesto por el constitucionalismo garantista, las denuncias a su falta de legitimidad democrática y su injerencia en la soberanía estatal pierden fuerza. Lógicamente esta estrategia se sustenta en los propios pronunciamientos que la Corte IDH ha realizado, los cuales esbozan la existencia de una suerte de democracia constitucional a nivel interamericano, en la que la soberanía estatal se vería limitada por los derechos reconocidos, tanto en los tratados internacionales como en las constituciones estatales. De tal forma que, dentro de un estricto margen de discrecionalidad, la Corte podría controlar las normas constitucionales con la finalidad de efectivizar los compromisos asumidos por los Estados en favor de sus ciudadanos.

Sin embargo, a pesar de los desarrollos en materia de protección de derechos humanos, la idea de una democracia constitucional interamericana aún se encuentra en construcción. Esto se hace evidente cuando la Corte IDH despliega una labor activista que la aleja de la legitimación que el constitucionalismo garantista encuentra en la sujeción a la CADH desde un enfoque positivista. Así se tiene que, a pesar de que la Corte se ha ceñido a un estrecho margen de discrecionalidad al controlar convencionalmente las cartas constitucionales, en otros casos ha sido proclive al activismo judicial, reforzando, de esta manera, las críticas dirigidas al ejercicio del control de convencionalidad.

A pesar de ello, las ideas desarrolladas en el presente trabajo pueden ser valiosas para plantear el problema de la dificultad contramayoritaria del control de convencionalidad en general, no solo el que es ejercido por la Corte IDH, sino también el que se despliega dentro de los ordenamientos estatales, pues recientemente los altos tribunales de la región, al emular las competencias de la Corte IDH, han empezado a controlar convencionalmente sus propias constituciones, lo que, contrario a lo que podría esperarse, produce efectos contraproducentes que ponen en riesgo la existencia del propio modelo democrático constitucional.

\section{Referencias bibliográficas}

Acosta, P. A. (2017). Ius Commune Interamericano. Brevísimas notas sobre el concepto de diálogo. En E. Ferrer MacGregor, A. Von Bogdandy, \& M. Morales Antoniazzi (Coords.), Ius Constitutionale Commune en América Latina. Textos básicos para su comprensión (pp. 371-384). México: Instituto de Estudios Constitucionales del Estado de Querétaro. https://archivos.juridicas.unam.mx/www/bjv/libros/10/4745/12.pdf

Alexy, R. (2006). Ponderación, control de constitucionalidad y representación. En R. Alexy, \& P. Andrés Ibáñez, Jueces y ponderación argumentativa (pp. 1-18). México: Instituto de Investigaciones Jurídicas de la UNAM. https:// archivos.juridicas.unam.mx/www/bjv/libros/5/2196/4.pdf

Álvarez Álvarez, F. (2003). Legitimidad democrática y control judicial de constitucionalidad. (Refutaciones al carácter contramayoritario del poder judicial). Díkaion(12). https://dikaion.unisabana.edu.co/index.php/ dikaion/article/view/1252/1364

Baldeni, G. (2010). Tratado de Derecho Constitucional (Vol. I). Buenos Aires: La Ley.

Bayón, J. C. (2005). Derechos, democracia y constitución. En M. Carbonell Sánchez (Coord.), Neoconstitucionalismo(s) (pp. 211-238). Madrid: Trotta.

Bickel, A. (1962). The least dangerous branch. The Supreme Court at the bar of politics. New Heaven: Yale University Press.

Diez-Picazo, L. M. (2006). Límites internacionales al poder constituyente. Revista Española de Derecho Constitucional(76), 9-32. https://recyt.fecyt.es/index.php/REDCons/article/view/48241

Ferrajoli, L. (2006). Garantismo. Una discusión sobre derecho y democracia. Madrid: Trotta.

Ferrajoli, L. (2008). Democracia y garantismo. Madrid: Trotta.

Ferrajoli, L. (2011). Poderes salvajes. La crisis de la democracia constitucional. Madrid: Trotta.

Ferrajoli, L. (2012). Constitucionalismo principialista y constitucionalismo garantista. Doxa. Cuadernos de Filosofía del Derecho(34), 15-53. https://rua.ua.es/dspace/bitstream/10045/32761/1/Doxa_34_02.pdf

Ferrajoli, L. (2013a). Principia iuris. Teoría del derecho y de la democracia. 1. Teoría del derecho. Madrid: Trotta. 
Ferrajoli, L. (2013b). Principia iuris. Teoría del derecho y de la democracia. 2. Teoría de la democracia. Madrid: Trotta.

Ferrajoli, L. (2014). La democracia a través de los derechos. El constitucionalismo garantista como modelo teórico y como proyecto político. Madrid: Trotta.

Ferrer Mac-Gregor, E. (2016). El control de convencionalidad como un vehículo para el diálogo judicial entre la Corte Interamericana de Derechos Humanos y los tribunales de América. Anuario de Derecho Constitucional Latinoamericano, 337-356.

Gargarella, R. (2011). La justicia frente al gobierno: sobre el carácter contramayoritario del poder judicial . Quito: Corte Constitucional para el Período de Transición.

Gargarella, R. (2013). Sin lugar para la soberanía popular. Democracia, derechos y castigo en el caso Gelman. SELA (Seminario en Latinoamerica de Teoría Constitucional y Política). https://digitalcommons.law.yale.edu/cgi/ viewcontent.cgi?article $=1124 \&$ context $=y l s \_$sela

Gargarella, R. (2017). ¿Por qué nos importa el diálogo? "La cláusula del 'no obstante”, “compromiso significativo" y audiencias públicas. Un análisis empático pero crítico. Revista del Centro de Estudios Constitucionales(5), 161-193. https://www.sitios.scjn.gob.mx/cec/sites/default/files/publication/ documents/2019-03/08_GARGARELLA_REVISTA_CEC_SCJN_NUM_5-179-211.pdf

Guastini, R. (2001). Estudios de Teoria Constitucional. Mexico: Fontarama.

Guastini, R. (2015). XII. Justicia constitucional v. democracia. En M. Carbonell Sánchez, H. Fix Fierro, \& D. Valadés (Coords.), Estado constitucional, derechos humanos, justicia y vida universitaria. Estudios en homenaje a Jorge Carpizo. Tomo III (pp. 337-342). México: Universidad Nacional Autónoma de México. https:// archivos.juridicas.unam.mx/www/bjv/libros/8/3824/16.pdf

Guastini, R. (2016). Lecciones de Derecho Constitucional. Lima: Ediciones Legales.

Hernández Castaño, D. P. (2014). Legitimidad democrática de la Corte Interamericana de Derechos Humanos en el control de convencionalidad. Bogotá: Universidad Externado de Colombia.

Hobbes, T. (2000). De cive. Madrid: Alianza.

Linares, S. (2008). La (i)legitimidad democrática del control judicial de las leyes. Madrid: Marcial Pons.

Montalvo Jäskeläinen, F. de. (2012). Las claúsulas notwithstanding y override del constitucionalismo canadiense. Teoría y Realidad Constitucional(30), 387-409. http://revistas.uned.es/index.php/TRC/article/ view/7013/6711

Nikken, P. (1987). La proteccion internacional de los derechos humanos: su desarrollo progresivo. Madrid: Civitas.

Nino, C. S. (1997). La constitución de la democracia deliberativa. Barcelona: Gedisa.

Nogueira Alcalá, H. (2009). La interpretacion constitucional de los Derechos Humanos. Lima: Ediciones Legales.

Pastori Fillol, A. (2011). Reflexiones sobre los problemas juridicos vinculados con la ejecucion de la sentencia de la Corte Interamericana de Derechos Humanos en el caso Gelman c/ Uruguay. Revista Internacional de Derechos Humanos(1), 181-195. https://www.revistaidh.org/ojs/index.php/ridh/article/view/11/9

Pino, G. (2018). El constitucionalismo de los derechos. Estructura y límite del constitucionalismo contemporáneo. Puno: Zela.

Salazar Ugarte, P. (2006). La democracia constitucional. Una radiografía teórica. México: Fondo de Cultura Económica.

Torres, N. (2016). Control de normas constitucionales por la Corte Interamericana de Derechos Humanos: Subsidiaridad, deferencia e impacto en la teoría del cambio constitucional. Anuario de investigacion del CICAJ, 279-317. http://repositorio.pucp.edu.pe/index/handle/123456789/175400

Von Bogdandy, A. (2015). Ius Constitutionale Commune en América Latina: una mirada a un constitucionalismo transformador. Revista Derecho del Estado(34), 3-50. https://revistas.uexternado.edu.co/index.php/derest/ article/view/4198/4643

Waldron, J. (2018). Contra el gobierno de los jueces. Ventajas y desventajas de tomar decisiones por mayoría en el Congreso y en los tribunales. Buenos Aires: Siglo Veintiuno. 